\title{
Prediction of strength and durability properties of HPC composites using Adaptive Neuro-fuzzy Inference System
}

\author{
Magudeaswaran. ${ }^{1}$, C. Vivek Kumar ${ }^{2}$, Rathod Ravinder $^{3}$ \\ ${ }^{1}$ Professor, Civil Engineering, Adithya Institute of Technology, Coimbatore, India. \\ ${ }^{2}$ Assistant Professor, Civil Engineering Department, GRIET, Hyderabad, Telangana, India. \\ ${ }^{3}$ Assistant Professor, Civil Engineering Department, GRIET, Hyderabad, Telangana, India.
}

\begin{abstract}
High-Performance Concrete (HPC) is a high-quality concrete that requires special conformity and performance requirements. The objective of this study was to investigate the possibilities of adapting neural expert systems like Adaptive Neuro-Fuzzy Inference System (ANFIS) in the development of a simulator and intelligent system and to predict durability and strength of HPC composites. These soft computing methods emulate the decision-making ability of human expert benefits both the construction industry and the research community. These new methods, if properly utilized, have the potential to increase speed, service life, efficiency, consistency, minimizes errors, saves time and cost which would otherwise be squandered using the conventional approaches.
\end{abstract}

\section{Introduction}

The substantial growth of population has been driven largely by increasing numbers of surviving people leads to the erection of flying buildings \& other structures with the accompanying savings costs in congested areas, the need for 'HPC' is now the current trend. Elite cement is a high-quality concrete that possesses immense workability, strength, and serviceability when compared to conventional concrete. These HPC composites contain common ingredients like cement, fine aggregate, and coarse aggregate with one or more of mineral admixtures materials such as fly ash, silica fume, and M-Sand and normally chemical admixture like superplasticizer are used to improve performance of the Concrete. Hence, durability and strength predicting models using the principles of artificial Intelligence is proposed. These models apply neural expert systems like flexible Neuro-Fuzzy Inference System (ANFIS) as a tool to predict the durability and strength of concrete. The MATLAB software was used to create a neural expert system that employs a highperformance language for technical computing. The ANFIS was found to be more efficient in terms of superior in terms of the accuracy of their predictive ability.

\section{Literature Review}

The literature review reviewed feasibility studies of neural expert system application for the decision- making capability of a human expert in complex concrete performance. The application of the neural expert system in the concrete field is a more user-friendly and more precise model. ANN and ANFIS models were retrieved to be most effective in assessing the durability and strength of HPC. It is suggested in the turn of events and the instance of higher exactness necessities. The advantages of ANN and ANFIS might be because the creation of the knowledge base inevitably on several nontrivial real-world problems. Faezehossadat Khademi et al (2016)., Forecasting the strength of recycled combination concrete utilizing Artificial Neural Network, adjustive NF logical thinking System, and Multiple statistical regression. Compressive quality of concrete, recognized mutually of the foremost crucial mechanical properties of cement, is recognized mutually of the foremost basic components for the standard affirmation of cement.. within the current study, 3 totally different data-driven models, i.e., Artificial Neural Network (ANN), adjustive Neuro-Fuzzy logical thinking System (ANFIS), and Multiple statistical regression (MLR) were accustomed predict the twenty eight MLR model failed to show a high level of capability in predicting the twenty eight days compressive strength of concrete. The current study complete that the estimation of twenty eight days compressive strength of recycled combination concrete was performed higher by ANN and ANFIS compared to MLR. 


\section{Materials and Methodology}

The magnitude relation of concrete collective proportion was 1:1.9:2.39; one half cement, 1.9 half fine aggregates, and 2.39 half coarse aggregates. Twelve any concrete mixtures were proportioned wherever M-sand (fine aggregate) with ash at the progressive interval five-hitter and cement with ash combined with oxide fume at a achieving rate. The collection of data entails the Ordinary cement of 53 Grade conformists to IS: 122691987, Coarse aggregates conforming to IS383-1970, M sand conformist to classifying zone II of IS: 383-1970 was used. The oxide fume confirming to ASTM C1240 was used for this experimentation and ash (Class F) confirming to IS 3812-1981. The command mixture was proportioned to have a 28-day compressive strength of $60 \mathrm{MPa}$ in line with BIS: 10262-1982. The composite of HPC was analyzed and chosen for making a model.

The study of the strength and durability properties of HPC had done. The method is listed as follows:

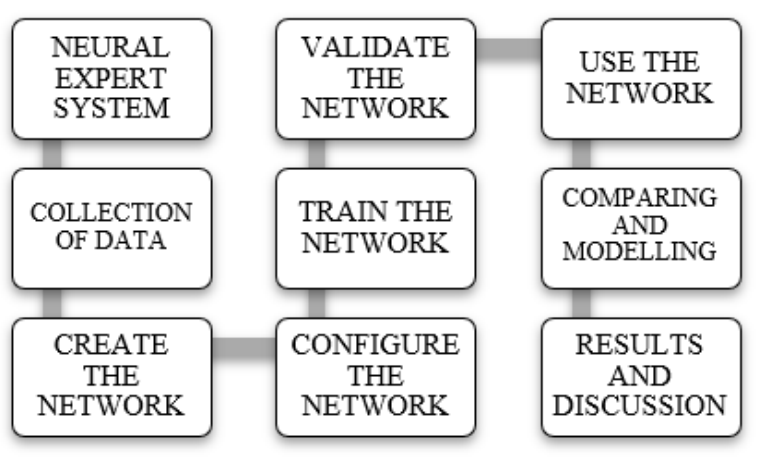

Fig. 1. Neural Expert System

\section{A. Collection of data}

The actual values of the compressive, split tensile and flexural strength, physical property modulus, water absorption, acid resistance, and fast chloride penetration check square measure recognized standard and for various proportions of silicon oxide fume like a pair of. $5 \%, 5 \%, 7.5 \%, 10 \%, 12.5 \%$, V-J Day and ash like five-hitter, $10 \%, 15 \%, 20 \%, 25 \%$, half-hour by experimental results. These investigational results square measure trained, tested, and valid applying Artificial Neural Network (ANN) and adaptative NeuroFuzzy illation System(ANFIS).

Table 1. Collection of data

\begin{tabular}{|c|c|c|}
\hline Input data & $\begin{array}{c}\text { Maximum } \\
\text { value }\end{array}$ & Target data \\
\hline Cement & $440 \mathrm{~kg} / \mathrm{m}^{3}$ & $\begin{array}{c}28 \text {-days compressive } \\
\text { strength }\end{array}$ \\
\hline Water & $145 \mathrm{litres}$ & Split tensile strength \\
\hline
\end{tabular}

\begin{tabular}{|c|c|c|}
\hline M-Sand & $839 \mathrm{~kg} / \mathrm{m}^{3}$ & Flexure strength \\
\hline Silica Fume & $2.5 \%$ & Modulus of elasticity \\
\hline Ages & $\begin{array}{c}1,3,7,14,28, \\
56,90 \text { days }\end{array}$ & Acid resistance test \\
\hline $\begin{array}{c}\text { Super } \\
\text { Plasticizer }\end{array}$ & 9.32 litres & $\begin{array}{c}\text { Rapid chloride penetration } \\
\text { test }\end{array}$ \\
\hline Flyash & $5 \%$ & Water absorption \\
\hline $\begin{array}{c}\text { Coarse } \\
\text { Aggregate }\end{array}$ & $1050 \mathrm{~kg} / \mathrm{m}^{3}$ & \\
\hline
\end{tabular}

\section{Adaptive Neuro-Fuzzy Inference System (ANFIS)}

An adjustive Neuro-Fuzzy abstract thought System (ANFIS) could be a style of ANN. It's recognized as a universal computer for countering to advanced issues. this technique combines each neural networks and logic principles, it'll secure the advantages of every terribly very specific framework. AN ANFIS is that the definite method of mapping from a given input to output applying symbolic logic.

Fuzzy logic is especially useful in the enhancement of expert systems. Expert systems are built by securing the expertise of humans. The dynamic behavior of a FIS is described by a set of linguistic explanation rules based on expert knowledge model comprising of a set of IF_THEN fuzzy rules. In the ANFIS model $70 \%$ of the total data were chosen for the training step, 30\% for checking step (testing and validating datasets). The total numbers of datasets are tabulated as follows:

Table 2: Datasets for ANFIS

\begin{tabular}{|c|c|c|c|}
\hline Datasets & Training & Checking & Total \\
\hline $\begin{array}{c}\text { 28 days Compressive } \\
\text { strength }\end{array}$ & 63 & 14 & 91 \\
\hline $\begin{array}{c}\text { 28-days Split tensile } \\
\text { strength }\end{array}$ & 9 & 2 & 13 \\
\hline $\begin{array}{c}\text { 28-days Flexural } \\
\text { strength }\end{array}$ & 9 & 2 & 13 \\
\hline $\begin{array}{c}\text { 28-days elasticity } \\
\text { modulus }\end{array}$ & 9 & 2 & 13 \\
\hline Water absorption test & 9 & 2 & 13 \\
\hline Acid resistance test & 9 & 2 & 13 \\
\hline $\begin{array}{c}\text { Rapid chloride } \\
\text { penetration test }\end{array}$ & 9 & & \\
\hline
\end{tabular}

\section{A. Modeling of HPC using Neuro-Fuzzy Design}

The basic structure of fuzzy illation system may be a prototypal that maps input characteristics to input membership functions, input membership functions to rules, rules to a group of output characteristics, output characteristics to output membership functions, and therefore the output membership functions to a singlevalued output related to the output. Such a system utilizes mounted membership functions that are chosen 
haphazardly and a rule structure that's essentially determined by the users understanding the qualities of the variables within the model.

As seen from the alternative fuzzy mentation GUIs, the structure of the membership performs varies on parameters and fixing these parameters shift the form of the membership operate. rather than merely seeing at the info to create a call the membership operate parameters, choose membership perform parameters instinctively exploitation these symbolic logic tool box applications.

In varied modelling things, it cannot distinguish the membership functions ought to take into account like merely from examining at information. Instead of choosing the parameters coupled with a given membership operate indiscriminately, these parameters may well be chosen to customise the membership functions to the input/output information to account

for the categories of variations within the information values. In such cases, it will apply the symbolic logic tool case neuro-adaptive understanding techniques integrated within the ANFIS command.

Before starting the FIS training, must stipulate an initial FIS model structure. In the modeling of HPC, there are eight input parameters and one output. The load knowledge command generates many variables among the area of the initial one hundred information points, use seventy information points as training data (datin and datout) and thirty data. The verifying data $\mathrm{i} / \mathrm{p}$ and $\mathrm{o} / \mathrm{p}$ pairs are denoted by chkdatin and chkdatout. Accept the composition of input data to be fed in MATLAB. When the quantity of input is with modesty massive larger than the four to 5 mathematical logic tool chest code extends a way that delivers some dimension decrease within the It generates a FIS structure applying the cluster algorithmic rule. First, establish a genfis choices possibility set for ablative cluster, stipulating 'Cluster Influence Range' vary property. The 'Cluster Influence Range' property suggests the range of impact of a cluster once considering the information area as a unit hypercube. istinctive little|alittle|atiny low $\}$ cluster radius generally yields many small clusters within the information, and outcomes in several rules. Stipulating an outsized cluster radius typically produces variety of huge clusters inside the data, and findings in fewer rules. opt=genfisOptions('SubtractiveClustering','ClusterInfluenc eRange',0.5); Create the FIS model by means of the training data and the specific alternatives:

\section{fismat $=$ genfis2(datin,datout,opt);}

The genfis 2 command uses a one-pass method that does not perform any iterative optimization. The model type for the created FIS structure is a single order Sugeno model with three rules. Authenticate the model. Here,
trnRMSE is the root mean square error of the system engendered by the training data.

\section{fuzout = evalfis (datin,fismat); \\ trnRMSE=norm (fuzout-datout)/sqrt(length(fuzout))}

At this point, First, attempt using a relatively short ANFIS coaching (20 epochs) in need of mistreatment validation knowledge, then check the following FIS model next to the testing knowledge. After the FIS is trained, confirm the model utilizing a Testing or checking data that diverges from the one to prepare the FIS. To certify the trained FIS the validation knowledge is managed for each checking and testing the FIS parameters. Here, chkRMSE is that the root mean sq.

\section{Results and Discussion}

It is supposed to make AN analytical/ mathematical model using Artificial Neural Network (ANN) and accommodative Neuro-Fuzzy illation System (ANFIS) designs for attaining sturdiness and strength. The developed model described as a simulation of HPC is the computer simulating system established by using MATLAB. In Artificial Neural Network, the different parameters of HPC were trained, tested, and validated using a feed-forward neural network. The SSE is the sum square error of the system employed for training, testing, and validating datasets.

An Adaptive Neuro-Fuzzy Inference System, the various parameters of HPC were trained and validated utilizing the subtractive clustering method. The RMSE is the root mean square error of the system used for training and checking datasets. The ANFIS models are incomparable as far as the exactness of their prescient capacity.

Table 3. R-value for ANN

\begin{tabular}{|c|c|c|}
\hline OUTPUT & TRAINING & $\begin{array}{c}\text { TESTING } \\
\& \\
\text { VALIDATING }\end{array}$ \\
\hline Compressive strength & 0.9970 & 0.9904 \\
\hline $\begin{array}{l}\text { 28-days split tensile } \\
\text { strength }\end{array}$ & 0.9991 & 0.9901 \\
\hline $\begin{array}{l}\text { 28-days flexural } \\
\text { strength }\end{array}$ & 0.9984 & 0.9910 \\
\hline $\begin{array}{c}\text { 28-days modulus of } \\
\text { elasticity }\end{array}$ & 0.9999 & 0.98160 \\
\hline Water absorption test & 0.9906 & 0.9880 \\
\hline Acid resistance test & 1.003 & 0.9880 \\
\hline $\begin{array}{l}\text { Rapid chloride } \\
\text { penetration test }\end{array}$ & 0.9971 & 0.9901 \\
\hline
\end{tabular}




\section{References}

1. MarekSłon'ski, "A comparison of model selection methods for compressive strength prediction of highperformance concrete using neural networks", Computers and Structures, Vol 88, Issue2010, pp 1248-1253.

2. Tao Ji, Tingwei Lin, Xujian Lin, "A concrete mix proportion design algorithm based on artificial neural networks" Issue 13 January 2006.

3. Osama Hodhod, Gamal A. Salama, Ain "Analysis of sulfate resistance in concrete based on Artificial Neural Networks and USBR4908-modeling” Issue 27 March 2013.

4. Vijay Pal Singh, Yogesh Chandra Kotiyal, "Prediction of compressive strength using artificial neural network" International Journal of Civil, Environmental, Structural, Construction and Architectural Engineering, Vol:7, No:12, Issue 2013.

5. Hamid Eskandari, Mortez Tayyebini, "Effect of 32.5 and 42.5 cement grades on ANN prediction of fibrocement compressive strength" International Conference on Industrial Engineering, ICIE Issue 2016.

6. Faezehossadat Khademi, Sayed Mohammadmehdi J amal,NeelaDeshpande,Shreenivasondhec, "Predicting strength of recycled aggregate concrete using artificial neural network, adaptive neuro-fuzzy inference system and multiple linear regression" International Journal of Sustainable Built Environment, Issue 17 September 2016.

7. O.A. Hodhoda, G. Salama, Ain "Simulation of expansion in cement based materials subjected to external sulfate attack" Shams Engineering Journal, Issue 1 July 2013.

8. O.A. Hodhoda, H.I. Ahmed, "Developing an artificial neural network model to evaluate chloride diffusivity in high performance concrete" Housing and Building National Research Center, Issue 10 September 2012.

9. Kasım Mermerdas, Mohamed Moafak Arbili "Explicit formulation of drying and autogenous shrinkage of concretes with binary and ternary blends of silica fume and fly ash" Construction and Building Materials, Vol 94 Issue 2015 pp 371-379.

10. M.B. Karakoça, R. Demirboğab,c , İ. Türkmena, İ. Canc "Expanded perlite aggregate on cyclic thermal loading of HSC and artificial neural network modeling" Scientia Iranica, Issue 21 November 2011.

11. Anoop K. Sooda, Raj K. Ohdarb, Siba S. Mahapatrac, "Experimental investigation and empirical modelling of FDM process for compressive strength improvement" Journal of Advanced Research Issue June 2012, pp 81-90 .

12. M. AminulHaque, Md.Rasel-Ul-Alam, "Non-linear models for the prediction of specified design strengths of concretes development profile" Housing and Building National Research Center, Issue 18 April 2016.
13. Salah A. Abo-El-Enein, Hamdy A. El-Sayed, Ali H. Ali , Yasser T. Mohammed ,Hisham M. Khater, Ahmed S. Ouda, "Physico-mechanical properties of high performance concrete using different aggregates in presence of silica fume" Housing and Building National Research Center, Issue 18 June 2013.

14. Adriana Trocoli AbdonDantas, Mônica Batista Leite, Koji de Jesus Nagahama"Prediction of compressive strength of concrete containing construction and demolition waste using artificial neural networks", Construction and Building Materials Vol 38, January 2013, pp. 717-722.

15. Ahmed M. Diab, Hafez E. Elyamany, Abd Elmoaty M. AbdElmoaty , Ali H. Shalan, Alexandria “ Prediction of concrete compressive strength due to long term sulfate attack using neural network" University Alexandria Engineering Journal, Issue 9 May 2014.

16. Seung-Chang Lee, "Prediction of concrete strength using artificial neural networks", Engineering Structures, Vol 25 Issue 2003 pp. 849-857.

17. Tummala Suresh Kumar, Kosaraju Satyanarayana, Materials Today: Proceeding, 26 (2), 3228-3233, (2020).

18. Hamid Eskandaria, Morteza Gharouni Nikb, Mohammad Mahdi Eidia "Prediction of mortar compressive strengths for different cement grades in the vicinity of sodium chloride using ANN" International Conference on Industrial Engineering, ICIE, Issue 2016.

19. O.A. Hodhoda, G.Salama "Simulating USBR4908 by ANN modeling to analyze the effect of mineral admixture with ordinary and pozzolanic cements on the sulfate resistance of concrete" Housing and Building National Research Center, Issue 6 February 2013.

20. Saif Salah Alquzweeni, "Artificial neural network model for predicting compressive strength of high strength concrete after burning" International Journal of Civil \& Environmental Engineering IJCEE-IJENS, Vol: 15 No: 06 .

21. N.K. Lee, H. Souri and H.K. Lee "Neural network application overview in prediction of properties of cement-based mortar and concrete". 